\title{
Hiatus Dissection and Posterior Crural Repair, Does it Change the Outcome of Sleeve Gastrectomy?
}

\author{
ABDELRAHMAN M. ELGHANDOUR, M.D.; HOSSAM S. ABDELRAHIM, M.D., M.R.C.S. and \\ AHMED F. AMER, M.D. \\ The Department of General Surgery, Faculty of Medicine, Ain Shams University
}

\begin{abstract}
Background: Laparoscopic Sleeve Gastrectomy (LSG) is one of the safest and most effective bariatric surgeries but carries the risk of gastro-esophageal reflux disease (GERD) and the hiatus hernia $(\mathrm{HH})$ development. The effect of $\mathrm{HH}$ identification and repair during LSG on GERD is controversial.

Aim of Study: In this study we evaluate the outcome of hiatal dissection and posterior crural repair if $\mathrm{HH}$ was found during LSG on GERD symptoms and post-operative weight loss.

Patients and Methods: This was a prospective study involving 100 patients who underwent LSG in Ain Shams University Hospitals, Patients were sequentially divided into 2 groups: Group A was the hiatal dissection group (no 50) in whom hiatal dissection was performed and posterior crural repair was done if $\mathrm{HH}$ was found while group B (no 50) was the non-hiatal dissection group in whom dissection stopped when the left crus of the diaphragm was reached, and sleeve gastrectomy (SG) was done alone. Both groups were followed for one year and compared regarding intra and post-operative complications, self-reported reflux symptoms and percentage of excess weight loss (\%EWL).
\end{abstract}

Results: Females represented $66 \%$ of patients, the mean age was 30.32 and 30.20 years, the mean pre-operative BMI was 41.12 and $43.2 \mathrm{~kg} / \mathrm{m}^{2}$ while the mean pre-operative health related quality of life index (HRQLI) score was 5.72 and 7.08 for group A and B respectively. Intra-operative blood loss for both groups was comparable, the mean operative time was significantly longer in group A which was $84.64 \mathrm{mins}$ in comparison to $49.92 \mathrm{mins}$ for group $\mathrm{B}$, there were no intraoperative complications in both groups. Hiatal dissection in group A revealed 8 cases (16\%) of $\mathrm{HH}$. Six cases of bleeding in both groups four in group A and two in group B, no leakage and one case of right lower limb DVT in group A two weeks after surgery. The mean GERD HRQLI scores were better for group A (with statistically significant difference at 9 months and highly significant difference at 12 months follow-up), while the \%EWL was highly significant better after the 6 th and 9 th months for group $\mathrm{A}$.

Conclusion: Active search for $\mathrm{HH}$ and its repair, if found, during SG has favorable outcome on post-operative reflux symptoms and weight loss with acceptable increase in the operative time.

Correspondence to: Dr. Abdelrahman M. Elghandour, E-Mail: abdelrahmanelghandour@gmail.com
Key Words: Sleeve gastrectomy - Hiatus hernia repair Reflux-Posterior crural repair - GERD.

\section{Introduction}

BARIATRIC surgery is the only effective longterm treatment for the global problem of morbid obesity. Every year thousands of bariatric surgeries are performed and the number is increasing significantly $[1,2]$.

In 2014 Sleeve Gastrectomy SG became the most commonly performed surgery for weight loss [3]. This is the result of excellent weight loss results and high safety profile for short and intermediate term when compared to other bariatric surgeries [4-6]. However, SG is associated with an increased incidence of gastroesophageal reflux disease GERD $[5,6]$. Many published series reported 2.1 to $21 \%$ incidence of denovo GERD on long-term followup for SG [1-6].

Hiatus hernia HH and GERD are more commonly seen in obese than non-obese population [7]. HH is more common in obese population and ranges from $23 \%$ to $52.6 \%$ and considered as one of the major risk factors for GERD development

The Laparoscopic Roux-en Y Gastric Bypass LRYGB is the first choice for obese patients with reflux symptoms $[\mathbf{9 , 1 0 ]}$. However, patients are usually in favor of LSG, which is felt by them to have lower morbidity with no long-term administration of vitamins and elemental nutrients which are not covered by health insurance systems [11]

It is also unclear if $\mathrm{HH}$ repair should be done for these patients if a SG was performed. Many surgeons believe that SG is a safe option for treatment of obesity if $\mathrm{HH}$ is found, only when combined with concomitant $\mathrm{HH}$ repair to reduce the incidence of postoperative reflux [12] 
The aim of the study is to evaluate the outcome of hiatal dissection and posterior crural repair if HH is found with LSG on post-operative reflux symptoms and weight loss.

\section{Patients and Methods}

This was a prospective study involving 100 patients who underwent primary LSG in Ain Shams University Hospitals, in the period between September 2018 and March 2021 with follow-up period of one year. Patients were divided into 2 groups: Group A was the hiatal dissection group (no 50) in whom hiatal dissection was performed and posterior crural repair was done if $\mathrm{HH}$ was found while group B (no 50) was the non-hiatal dissection group in whom dissection stopped when the left crus of the diaphragm was reached, and SG done alone.

All patients were fit for general anesthesia with body mass index BMI more than $40 \mathrm{~kg} / \mathrm{m}^{2}$ or more than $35 \mathrm{~kg} / \mathrm{m}^{2}$ with associated co-morbidities with history of failed previous diet and conservative measures for weight loss. Patients unfit for general anesthesia, those with history of severe GERD symptoms (pre-operative GERD HRQLI score more than 12), and patients with already known $\mathrm{HH}$ and diagnosed by upper GIT endoscopy or with history of previous gastric surgeries were excluded from the study.

The study was approved from the Research Ethics Committee (REC), General Surgery Department, Ain Shams University.

All patient signed an informed pre-operative consent after clear description of the procedure.

Pre-operative preparation was done for all patients with good history and thorough clinical examination as per standard in our team.

The patients received a prophylactic dose of enoxaparin sodium (Clexane $\left.{ }^{\circledR}\right) 40$ iu SC the night before surgery.

All 100 cases were done laparoscopic under general anesthesia in a French antitrendlenberg position (supine with open legs) using three to four ports.

Creation of pneumoperitoneum was done through an insufflation needle put in the left hypochondrium, left midclavicular line just below the costal margin and then three or four ports were introduced as follow:

- $12 \mathrm{~mm}$ visiport above and slightly to the left of the umbilicus for the camera and the stapler.
$-5 \mathrm{~mm}$ right working port in the left hypochondrium.

- $15 \mathrm{~mm}$ left working port in the right hypochondrium.

- An optional $5 \mathrm{~mm}$ epigastric port for the liver retraction if needed.

The procedure was started by dissecting and sealing the vessels around the greater curve of the stomach using the LigaSureTM; Covidien, Mansfield, MA, USA sealing device starting around 4 $\mathrm{cm}$ proximal to the pylorus till the angle of His. Complete mobilization of the fundus was done by sealing and transecting the short gastric vessels till the left crus of the diaphragm Fig. (1).

In the hiatal dissection Group A dissection was continued, and the left diaphragmatic crus was completely exposed and the gastro-esophageal junction was identified, HH diagnosis was established according to the following protocol:

- Careful inspection of the relation of the gastroesophageal junction to the hiatus without an orogastric tube in place to diagnose if there is a sliding HH, Fig. (2). If the GEJ was higher above the level of the diaphragmatic hiatus and/or a widely separated crura were found, the HH diagnosis was completed.

- If the $\mathrm{HH}$ was not clear through the previous method, dissection of the fat pad exposing the angle of His was done to clearly identify the GEJ at that level and if it was above the level of the diaphragm, thus diagnosis of the $\mathrm{HH}$ was carried out.

- So, HH diagnosis was obtained only through intra-operative diagnosis.

When the diagnosis of HH was completed, the gastro-hepatic ligament was dissected, and the right crus of the diaphragm was exposed. Thereafter, the diaphragmatic crura were dissected completely till the mediastinal space and the lower end of the esophagus was mobilized into the abdominal cavity for at least $3 \mathrm{~cm}$ below the hiatus level preserving both vagal nerves Fig. (3). After that, posterior crural repair was done using 3 or more interrupted 2-0 non absorbable prolene sutures with a 36 Fr bougie inside the esophagus crossing the diaphragmatic hiatus to avoid narrowing Fig. (4).

In the non-hiatal dissection Group B dissection stopped when the left crus of the diaphragm was identified.

In both groups the stomach was resected with the Endo GIATMcovidien staplers parallel to a 36 
Fr bougie along the lesser curve. Starting with the first green reload $60-4.8 \mathrm{~mm}$ about $4 \mathrm{~cm}$ from the pyloric ring, and then another green reload was used when needed. Stapling was continued using another 3 to 5 blue reloads 60-3.5 mmwith a special interest to avoid narrowing the incisura angle and to meticulously achieve a uniform sleeved stomach tube by symmetrical stapling of the anterior and posterior gastric walls without any kink or twist.

Hemostasis was completed with titanium clips then methylene blue dye test was used for determination of staple-line integrity and the resected stomach was removed through the right hypochondrial $15 \mathrm{~mm}$ port. Finally, an intrabdominal drain was put through the left hypochondrial $5 \mathrm{~mm}$ port and wounds were closed.

\section{Post-operative care:}

Pain was controlled by IV narcotics, nonsteroidal anti-inflammatory drugs and acetaminophen. All patients received IV $4 \mathrm{mg}$ Ondansetron (Zofran®) twice daily. Precautions were taken to guard against deep venous thrombosis by wearing elastic stocking starting before surgery, adequate hydration, early mobilization two hours after recovery from anesthesia and all patients continued venous thrombo-embolism prophylaxis as early as possible after surgery for two weeks. Oral sips of water and clear liquids were started 6-12 hours

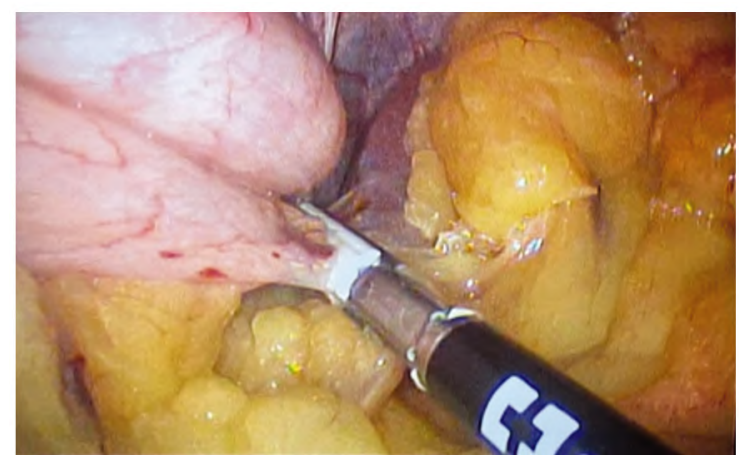

Fig. (1): Complete fundus mobilization by dissecting and sealing the short gastric vessels.

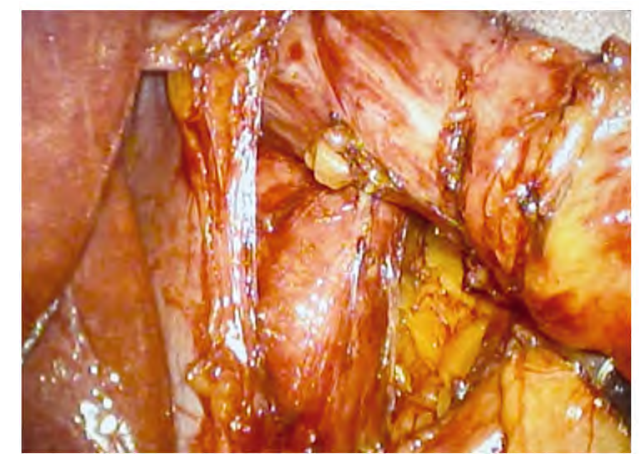

Fig. (3): Complete crural dissection with complete mobilization of the esophagus into the abdominal cavity for at least $3 \mathrm{~cm}$. after surgery and continued for two weeks, pureed soft diet for two more weeks, after that normal diet was started with special precautions. All patients were discharged on daily dose of Proton pump inhibitors for three months, multi-vitamins for six months and treatment of hypertension and diabetes, if present, according to medical instructions.

\section{Post-operative follow-up:}

All patients underwent regular follow-up visits after two weeks, first month and then monthly for one year. Post-operative weight loss was assessed by calculating \%EWL at 6, 9 and 12 months. Selfreported reflux symptoms were assessed by running GERD HRQL questionnaire once pre-operative and then at the same intervals.

The GERD HRQL questionnaire Fig. (5) was used and validated for measurement of the changes in typical GERD symptoms as heart burn and regurgitation in response to a specific medical or surgical treatment [13]

Heartburn Score: Total individual score to questions 1-6.

- Worst heartburn symptoms gives a score of 30 .

- No heartburn symptoms gives a score of 0 .

- Scores of $\leq 12$ with each individual question not exceeding 2 indicate heartburn elimination.

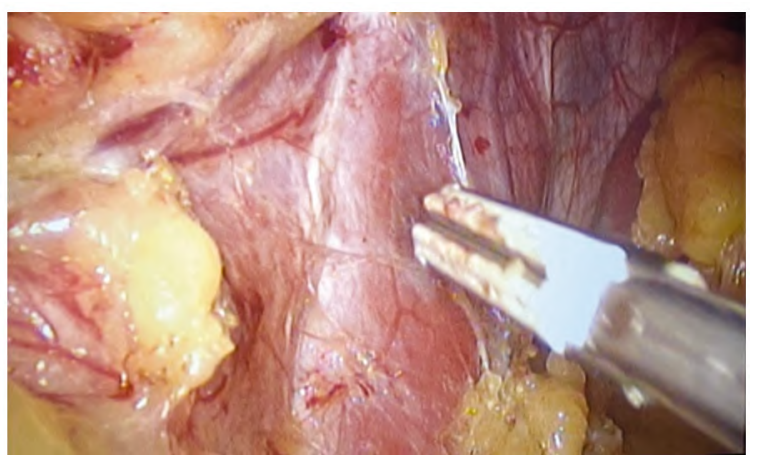

Fig. (2): Careful inspection of GEJ without the orogastric tube to identify the presence of $\mathrm{HH}$.

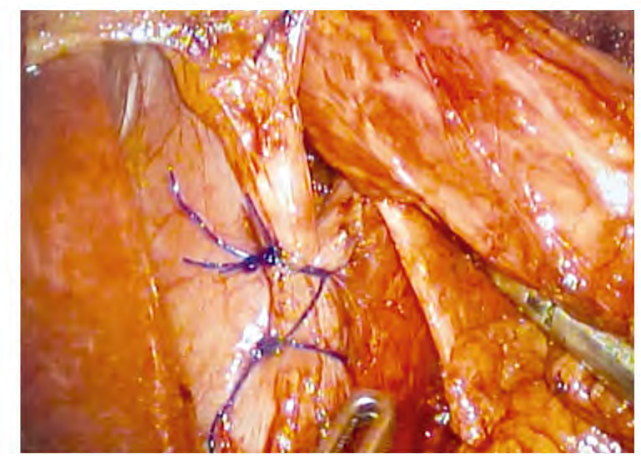

Fig. (4): Posterior crural repair with 2-0 prolene sutures with $36 \mathrm{fr}$ bougie inside the esophagus. 
GERD-Health Related Quality of Life Questionnaire (GERD-HRQL)

Institution: Patient ID:___ Date / /

$\square$ On PPIs $\square$ Off PPIs If off, for how long? days/months

Scale:

$0=$ No symptom.

$1=$ Symptoms noticeable but not bothersome

$2=$ Symptoms noticeable and bothersome but not every day.

3 = Symptoms bothersome every day.

$4=$ Symptoms affect daily activity.

$5=$ Symptoms are incapacitating to do daily activities.

Please check the box to the right of each question which best describes your experience over the past 2 weeks

1. How bad is the heartburn?

2. Heartburn when lying down?

3. Heartburn when standing up?

4. Heartburn after meals?

5. Does heartburn changes our diet?

6. Does heartburn wake you from sleep?

Fig. (5): GERD HRQLI questionnaire [13] .

\section{Data management and analysis:}

Data was revised, codedand analyzed utilizing SPSS version 26 for Windows (SPSS Inc, Chicago, IL, USA). Quantitative data was tested for normality with Shapiro-Wilk test and described as mean and standard deviation (SD). Student $t$-test was used for comparing quantitative variables between two study groups. Qualitative data was processed as frequencies (n) and percentage (\%). Chi-square and Fisher exact tests were used to test the association between qualitative variables. $p$-value $\leq 0.05$ was considered significant.

\section{Results}

A total of 100 adult patients were included in the study, females represented $66 \%$ of them, the mean age was 30.32 and 30.20 years, the mean pre-operative BMI was 41.12 and $43.2 \mathrm{~kg} / \mathrm{m}^{2}$ while the mean pre-operative GERD HRQLI score was 5.72 and 7.08 for group A and B respectively. Preoperative and demographic data were recorded in Table (1) and show no statistically significant difference between both groups.

Intra-operative blood loss was comparable in both groups. Even thoughthe mean operative time was significantly longer in group A which was 84.64mins in comparison to $49.92 \mathrm{mins}$ for group $\mathrm{B}$, there were no intra-operative complications in both groups. Hiatal dissection in group A revealed 8 cases $(16 \%)$ of hiatus hernia which were managed and repaired, operative data were shown in Table (2).

Post-operative data were shown in Table (3), six cases of bleeding in both groups four in group $\mathrm{A}$ and two in group B detected by draining of more than $300 \mathrm{cc}$ of fresh blood which were successfully managed conservatively by close monitoring of vital data, IV infusion of Tranexamic acid and Ethamsylate, two of them required blood and fresh frozen plasma transfusion. No leakage in our series and one case of right lower limb DVT two weeks after surgery in group A which was managed by therapeutic doses of anticoagulation.

The mean post-operative GERD HRQL scores were better for group A (with statistically significant difference at 9 months and highly significant difference at 12 months follow-up) Fig. (6) and Table (4), both groups showed no cases with GERD HRQLI scores more than 12 at 6 months followup while at 9 months follow-up the patients of group B showed 4 (8\%) cases with positive GERD symptoms $>12$ compared to none $(0 \%)$ in group A which is statistically significant, and when comparing the results at 12 months group B had 9 $(18 \%)$ of cases compared with one case $(2 \%)$ in group A which is highly significant, the result were shown in Table (5).

When comparing at the same intervals there was highly significant better \%EWL results after the 6 th and 9 th months for group A while it was comparable at 12 th months Fig. (7), the results were shown in Table (4).

Table (1): Pre-operative data.

\begin{tabular}{|c|c|c|c|c|c|}
\hline & $\begin{array}{l}\text { Group A } \\
(50)\end{array}$ & $\begin{array}{l}\text { Group B } \\
(50)\end{array}$ & $\begin{array}{c}\text { Test } \\
\text { value }\end{array}$ & $\begin{array}{c}p- \\
\text { value }\end{array}$ & Sig. \\
\hline Age $($ mean $\pm S D)$ & $30.32 \pm 9.82$ & $30.20 \pm 8.65$ & $0.046^{*}$ & 0.964 & NS \\
\hline \multicolumn{6}{|l|}{$\operatorname{Sex}($ no, \%): } \\
\hline Male & $18(36 \%)$ & $16(32 \%)$ & $0.089 * *$ & 0.765 & NS \\
\hline Female & $32(64 \%)$ & $34(68 \%)$ & & & \\
\hline $\mathrm{BMI}($ mean $\pm \mathrm{SD})$ & $41.12 \pm 4.77$ & $43.2 \pm 4.33$ & $1.614^{*}$ & 0.113 & NS \\
\hline $\begin{array}{l}\text { GERD HRQL } \\
(\text { mean } \pm \text { SD })\end{array}$ & $5.72 \pm 3.39$ & $7.08 \pm 3.14$ & $1.474^{*}$ & 0.147 & NS \\
\hline
\end{tabular}


Table (2): Operative data.

\begin{tabular}{|c|c|c|c|c|c|}
\hline & $\begin{array}{c}\text { Group A } \\
(50)\end{array}$ & $\begin{array}{l}\text { Group B } \\
(50)\end{array}$ & $\begin{array}{c}\text { Test } \\
\text { value }\end{array}$ & $\begin{array}{c}p- \\
\text { value }\end{array}$ & Sig. \\
\hline $\begin{array}{l}\text { Operative time } \\
\text { min (mean } \pm \text { SD) }\end{array}$ & $84.64 \pm 10.94$ & $49.92 \pm 6.56$ & $13.612 *$ & 0.001 & HS \\
\hline $\begin{array}{l}\text { Blood loss ml } \\
\quad(\text { mean } \pm \text { SD })\end{array}$ & $28.2 \pm 4.34$ & $25.36 \pm 8.55$ & $1.481 *$ & 0.148 & NS \\
\hline $\begin{array}{l}\text { Intraoperative } \\
\text { complications }\end{array}$ & 0 & 0 & & & \\
\hline $\begin{array}{l}\text { Hiatus hernia } \\
\text { detected }\end{array}$ & $8(16 \%)$ & & & & \\
\hline
\end{tabular}

*Student $t$-test. HS: Highly significant.

Table (3): Post-operative complications.

\begin{tabular}{lccccc}
\hline & $\begin{array}{c}\text { Group A } \\
(50)\end{array}$ & $\begin{array}{c}\text { Group B } \\
(50)\end{array}$ & $\begin{array}{c}\text { Test } \\
\text { value }\end{array}$ & $\begin{array}{c}p \text { - } \\
\text { value }\end{array}$ & Sig. \\
\hline Bleeding no (\%) & $4(8 \%)$ & $2(4 \%)$ & $0.355^{* *}$ & 0.552 & NS \\
Leakage no (\%) & $0(0 \%)$ & $0(0 \%)$ & & & \\
Thromboembolism & $1(2 \%)$ & $0(0 \%)$ & $1.020^{* *}$ & 0.312 & NS \\
$\quad$ no (\%) & & & & & \\
\hline
\end{tabular}

**Chi-square test.

Table (4): Follow-up of HRQL and \%EWL.

\begin{tabular}{|c|c|c|c|c|c|}
\hline & $\begin{array}{l}\text { Group A } \\
(50)\end{array}$ & $\begin{array}{l}\text { Group B } \\
(50)\end{array}$ & $\begin{array}{c}\text { Test } \\
\text { value }\end{array}$ & $\begin{array}{c}p- \\
\text { value }\end{array}$ & Sig. \\
\hline $\begin{array}{l}\text { GERD HRQL } \\
6 \text { months } \\
\text { (Mean } \pm \text { SD) }\end{array}$ & $6.04 \pm 3.6$ & $6.20 \pm 4.16$ & $0.137^{*}$ & 0.892 & NS \\
\hline $\begin{array}{l}\text { GERD HRQL } \\
9 \text { months } \\
\text { (Mean } \pm \text { SD) }\end{array}$ & $5.32 \pm 2.99$ & $8.20 \pm 5.22$ & $1.894^{*}$ & 0.026 & S \\
\hline $\begin{array}{l}\text { GEDR HRQL } \\
12 \text { months } \\
\text { (Mean } \pm \text { SD) }\end{array}$ & $3.52 \pm 1.42$ & $9.48 \pm 6.02$ & $4.817 *$ & $<0.001$ & HS \\
\hline $\begin{array}{l}\text { \%EWL } 6 \text { months } \\
\text { (Mean } \pm \text { SD) }\end{array}$ & $58.22 \pm 6.33$ & $48.28 \pm 7.86$ & $4.924 *$ & $<0.001$ & HS \\
\hline $\begin{array}{l}\text { \%EWL } 9 \text { months } \\
\text { (Mean } \pm \text { SD) }\end{array}$ & $76.96 \pm 4.35$ & $68.58 \pm 5.23$ & $6.156^{*}$ & $<0.001$ & HS \\
\hline $\begin{array}{l}\text { \%EWL } 12 \text { months } \\
(\text { Mean } \pm \text { SD) }\end{array}$ & $85.76 \pm 3.54$ & $84.08 \pm 5.58$ & $1.271 *$ & 0.211 & NS \\
\hline
\end{tabular}

*Student $t$-test. S: Significant.

Table (5): GERD HRQLI score indicative for significant GERD symptoms (total score is more than 12 or any individual question is more than 2).

\begin{tabular}{llllll}
\hline & $\begin{array}{c}\text { Group A } \\
(50)\end{array}$ & $\begin{array}{c}\text { Group B } \\
(50)\end{array}$ & $\begin{array}{c}\text { Test } \\
\text { value }\end{array}$ & $\begin{array}{c}p \text { - } \\
\text { value }\end{array}$ & Sig. \\
\hline GERD HRQL & 0 & 0 & & & \\
$\quad 6$ months no (\%) & & & & & \\
$\begin{array}{c}\text { GERD HRQL } \\
9 \text { months no (\%) }\end{array}$ & $0(0 \%)$ & $4(8 \%)$ & 4.348 & 0.037 & $\mathrm{~S}$ \\
$\begin{array}{c}\text { GERD HRQL } \\
12 \text { months no (\%) }\end{array}$ & $1(2 \%)$ & $9(18 \%)$ & 8.000 & 0.005 & HS \\
\hline
\end{tabular}

Chi-square test.

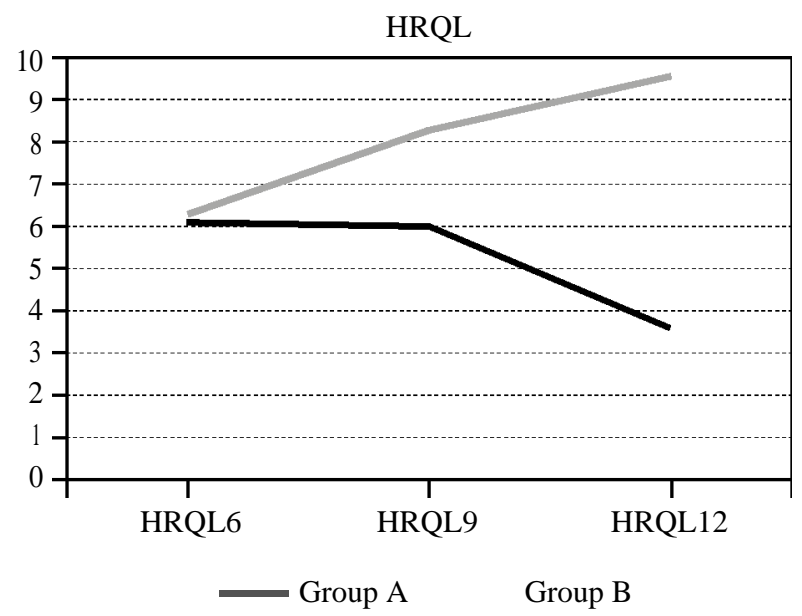

Fig. (6): GERD HRQL in both groups.

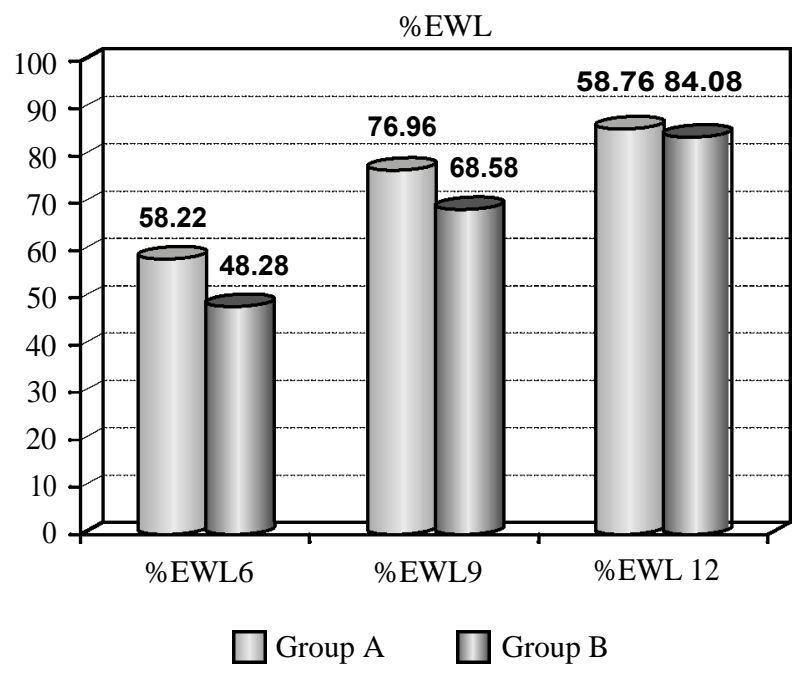

Fig. (7): \%EWL in both groups.

\section{Discussion}

Since the LSG was first presented by Marceau in 1993, as a part of bilio-pancreatic diversion, the procedure is gaining popularity, and many studies were done for evaluating its long-term outcome and its impact on health and lifestyle [14]

LRYGB is the preferred operation for obese patients with severe reflux as LSG may worsen the reflux symptoms, but LSG is technically easier with less morbidity and mortality rated and has no risk of marginal ulcers, internal hernias and doesn't need life-long vitamins replacement $[15,16]$.

Many bariatric experts avoid performing LSC for patients with reflux and/or $\mathrm{HH}$ as it may worsen the GERD symptoms and still the association between LSG and GERD is controversial [17]

Unfortunately, the data about combined LSG and $\mathrm{HH}$ repair is not clear with some authors 
demonstrating improvement of GERD symptoms and others demonstrating worsening $[18,19]$

In this study, the technique for adequate search and repair of hiatus hernia if found was adopted in all hiatal dissection group cases and $16 \%$ of them were found to have a hiatus hernia for repair. This comes in agreement with the results of Sheppard et al., who reported that $15 \%$ of 378 patients underwent SGhad significant $\mathrm{HH}$ that needed repair [20].

On the other hand, Daes et al., stated that of the 137 patients treated with LSG, 25.3\% had HH and was repaired during the procedure. No one of the HH repair with LSG group reported postoperative GERD symptoms [21]. This comes in agreement with our results as it was reported that patients with hiatal dissection and concomitant $\mathrm{HH}$ repair had better post-operative reflux symptoms.

The results came in agreement with Soricelli et al., who compared a group of patients who underwent LSG alone with another group who was diagnosed with $\mathrm{HH}$ and underwent LSG and $\mathrm{HH}$ repair, GERD symptoms significantly improved in $80 \%$ of $\mathrm{HH}$ repair group and with eighteen months follow-up, GERD symptoms developed in $22.9 \%$ in LSG alone group while the HH and LSG group had no denovo reflux symptoms. The authors concluded that HH repair with LSG gives a good management for obese patients with reflux symptoms who are candidate for bariatric surgery [23]

The identification and management of $\mathrm{HH}$ with SG were given more importance by time. In 2012 the International SG Experts Panel Consensus stated the guidelines which were based upon 12,000 cases experience, they determined that the phrenoesophageal membrane should always be dissected, and the greater curve side of the stomachshould be examined for the presence or absence of $\mathrm{HH}$. Thus, $83 \%$ of the surgeons recommended precise intra-operative identification of the $\mathrm{HH}$ and $82 \%$ of them recommended posterior crural repair if found [22]

While SG is the most popular weight loss operation, one of its disadvantages is the development of denovo reflux or worsening of pre-existing symptoms. This may be due to either increased intra-gastric pressure in the sleeved stomach tube, disrupting the sling fibers around the GEJ or decreasing the resting pressure of the GEJ which may be responsible for the high incidence of denovo or worsening of GERD symptoms following LSG [24]. So, hiatal dissection with SG and repair of $\mathrm{HH}$ if found may help in decreasing and/or pre- venting the reflux symptoms which may be a result of the procedure itself.

In a study done by Maher El Chaar et al., it was found that higher \%EWL at three and six months (with statistically significant difference at 6 months) in patients who underwent SG and $\mathrm{HH}$ compared to patients with SG alone [25] which comes in comparison with our results, as we reported higher \%EWL at six, nine and twelve months (with a statistically significant difference at 6 and 9 months) for the hiatal dissection group. The higher excess weight loss among group A patients is likely due to better mobilization of the gastric fundus of the left crus which can result in more ability to resect the redundant fundus or due to more tight hiatus in the patients underwent $\mathrm{HH}$ repair which may add to the restriction of the procedure compared to the non-hiatal dissection group patients.

We believe that the best way for intra-operative identification of HH during LSG is proper and meticulous hiatal dissection, as the visual inspection alone for fingerprinting is not reliable and a potential HH may be obscured by a self-retaining liver retractor or a large pad of fat at the level of GEJ [18]. Therefore, proper hiatal dissection should be done routinely and any $\mathrm{HH}$ should be repaired during LSG. Also, we adopted the same technique for hiatus dissection and $\mathrm{HH}$ repair in all cases of Group A which was safe and effective although the operative time was significantly longer, but this didn't lead to more intra or post-operative complications.

\section{Limitations:}

Our study had some limitations, first, it relied on patient self-reported reflux symptoms rather than objective data. As we believe that the gold standards for GERD evaluation are upper GIT endoscopy and $\mathrm{pH}$ testingto measure the extent of mucosal damage and exposure to gastric acidity. Our study, however, was designed to measure patient satisfaction which was mainly related to patient symptoms. So, data are based only on selfreported reflux symptoms and questionnaires which are completed by patients and may be subjected to recall bias which may over or underestimate GERD symptoms. Also, the study lacks objective evaluation of GERD based on 24 hrs. pH monitoring which, however, valuable, is so difficult and not covered by health insurance system.

Furthermore, the effect of hiatal dissection and HH repair on post-operative EWL should be studied in future research with larger samples and longer 
follow-up to reach a meaningful and definitive conclusion.

\section{Conclusion:}

Active search for $\mathrm{HH}$ and its repair, if found, during LSGis safe and has favorable outcome on post-operative reflux symptoms and weight loss with acceptable increase in the operative time.

No conflict of interest to be declared.

\section{References}

1- BUCHWALD H.: Consensus Conference Panel. Consensus conference statement bariatric surgery for morbid obesity: Health implications for patients, health professionals, and third-party payers. Surg. Obes. Relat. Dis., 1 (3): 371-81, 2005.

2- BUCHWALD H., AVIDOR Y., BRAUNWALD E., et al.: Bariatric surgery: A systematic review and meta-analysis. JAMA, 292: 1724-37, 2004.

3- ANGRISANI L. 2014: The year of the sleeve supremacy. Obes. Surg., 27 (6): 1626-27, 2017.

4- BOZA C., SALINAS J., SALGADO N., et al.: Laparoscopic sleeve gastrectomy as a stand-alone procedure for morbid obesity: Report of 1,000 cases and 3-year followup. Obes Surg., 22: 866-71, 2012.

5- BRETHAUER S.A., HAMMEL J.P. and SCHAUER P.R.: Systematic review of sleeve gastrectomy as staging and primary bariatric procedure. Surg. Obes. Relat. Dis., 5 (4): 469-75, 2009.

6- AURORA A.R., KHAITAN L. and SABER A.A.: Sleeve gastrectomy and the risk of leak: A systematic analysis of 4,888 patients. Surg. Endosc., 26 (6): 1509-15, 2012.

7- SORICELLI E., IOSSA A., CASELLA G., ABBATINI F., CALì B. and BASSO N.: "Sleeve gastrectomy and crural repair in obese patients with gastroesophageal reflux disease and/or hiatal hernia," Surgery for Obesity and Related Diseases, 9 (3): 356-361, 2013.

8- CARABOTTI M., AVALLONE M., CEREATTI F., et al.: Usefulness of upper gastrointestinal symptoms as a driver to prescribe gastroscopy in obese patients candidate to bariatric surgery. A prospective study. Obes. Surg., 26 (5): 1075-80, 2016.

9- CHE F., NGUYEN B., COHEN A., et al.: Prevalence of hiatal hernia in the morbidly obese. Surg. Obes. Relat. Dis., 9 (6): 920-924, 2013.

10- TAI C.M., HUANG C.K., LEE Y.C., et al.: Increase in gastroesophageal reflux disease symptoms and erosive esophagitis 1 year after laparoscopic sleeve gastrectomy among obese adults. Surg. Endosc., 27 (4): 1260-6, 2013.

11- POMP A.: Comment on: Sleeve gastrectomy and crural repair in obese patients with gastroesophageal reflux disease and/or hiatal hernia. Surg. Obes. Relat. Dis., 9 (3): 361-2, 2013.

12- DAES J., JIMENEZ M.E., SAID N., et al.: Laparoscopic sleeve gastrectomy: Symptoms of gastroesophageal reflux can be reduced by changes insurgical technique. Obes. Surg., 22 (12): 1874-9, 2012.

13-VELANOVICH V.: The development of the GERD-HRQL symptom severity instrument. Dis. Esophagus, 20 (2): 130-4, 2007.

14- ARIDI H., ASALI M., FOUANI T., ALAMI R. and SAFADI B.: Gastroesophageal Reflux Disease After Laparoscopic Sleeve Gastrectomy with Concomitant Hiatal Hernia Repair: An Unresolved Question. Obes. Surg., 27: 2898-2904, 2017.

15- CHIU S., BIRCH D.W., SHI X., SHARMA A.M. and KARMALI S.: Effect of sleeve gastrectomy on gastroesophageal reflux disease: A systemic review. Surg. Obes. Rela. Dis., 7 (4): 510-5, 2011.

16- YEHOSHUA R.T., EIDELMAN L.A., STEIN M., et al.: Laparoscopic sleeve gastrectomy - volume and pressure assessment. Obes. Surg., 18 (9): 1083-8, 2008.

17- BRAGHETTO I., CSENDES A., KORN O., VALLADARES H., GONZALEZ P. and HENRÍQUEZ A.: Gastroesophageal reflux disease after sleeve gastrectomy. Surg. Laparosc. Endoscopy, 25: 1898-2906, 2016.

18- SORICELLI E., IOSSA A., CASELLA G., ABBATINI F., CALI B. and BASSO N.: Sleeve gastrectomy and crural repair in obese patients with gastroesophageal reflux disease and/or hiatal hernia. Surg. Obes. Relat. Dis., 9 (3): 356-62, 2013.

19- DU PREE C.E., BLAIR K., STEELE S.R. and MARTIN M.J.: Laparoscopic sleeve gastrectomy in patients with preexisting gastroesophageal reflux disease. JAMA Surg., 149 (4): 328-34, 2014.

20- SHEPPARD C.E., SADOWSKI D.C., de GARA C.J., et al.: Rates of reflux before and after laparoscopic sleeve gastrectomy for severe obesity. Obes. Surg., 25: 763-8, 2015.

21- DAES J., JIMENEZ M.E., SAID N., et al.: Improvement of gastroesophageal reflux symptoms after standardized laparoscopic sleeve gastrectomy. Obes. Surg., 24: 53640, 2014.

22- SORICELLI E., CASELLA G., RIZZELLO M., et al.: Initial experience with laparoscopic crural closure in the management of hiatal hernia in obese patients undergoing sleeve gastrectomy. Obes. Surg., 20: 1149-53, 2010.

23- ROSENTHAL R.J., DIAZ A.A., ARVIDSSON D., BAKER R.S., BASSO N., et al.: International sleeve gastrectomy expert panel consensus statement: Best practice guidelines based on experience of $>12,000$ cases. Surg. Obesity Related Dis., 8 (1): 8-19, 2012.

24- CARTER P.R., Le BLANC K.A., HAUSMANN M.G., KLEINPETER K.P., de BARROS S.N., JONES S.M.: Association between gastroesophageal reflux disease and laparoscopic sleeve gastrectomy. Surg. Obes. Relat. Dis., 7 (5): 569-72, 2011.

25- EL CHAAR M., HAMMOUD N., EZEJI G., CLAROS L., MILETICS M. and STOLTZFUS J.: Laparoscopic sleeve gastrectomy versus laparoscopic Roux-en-Y gastric bypass: A single center experience with 2 years followup. Obes. Surg. Feb., 25 (2): 254-62, 2015. 


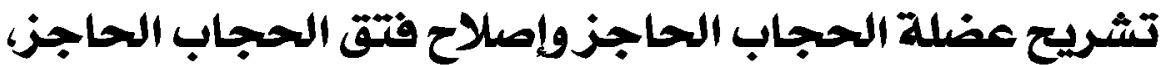

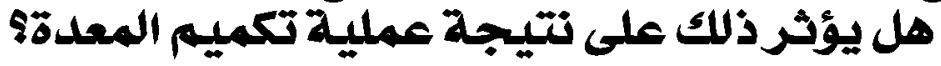

الخلفية: استئصال المعدة بالمنظار آمن وبسيط وفعال، لكنه ينطوى على خطر حدوث ارتجاع في المرىئ وفتق الحجاب الحاجز. أن تأثير

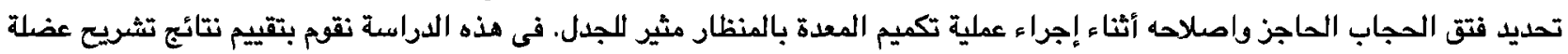

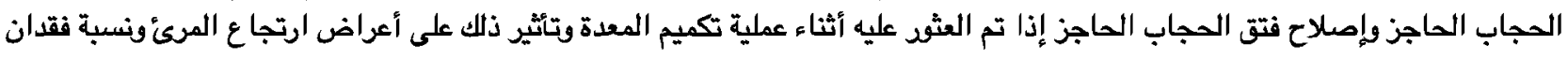

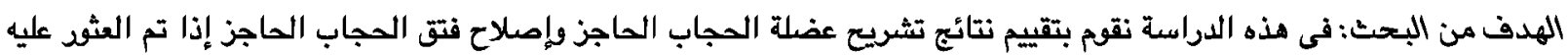

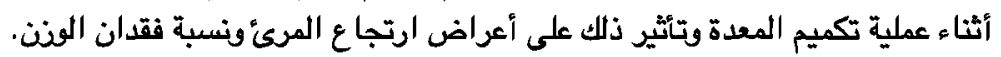

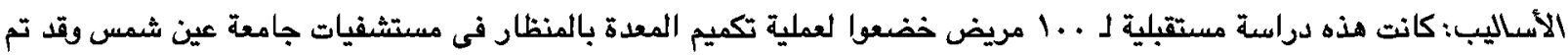

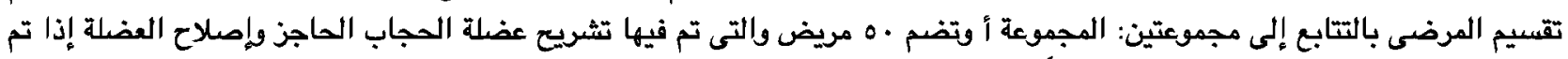

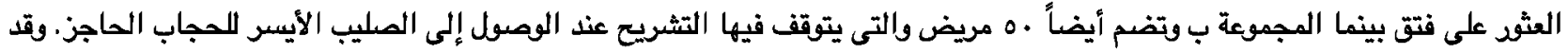

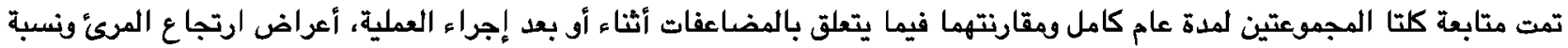
نقصان الونن.

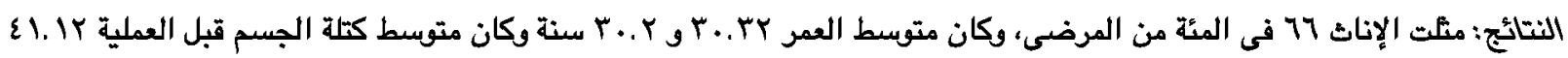

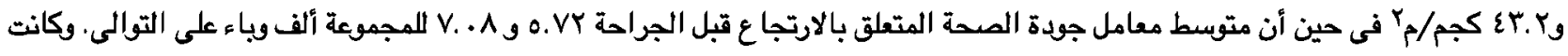

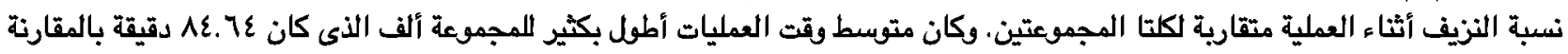

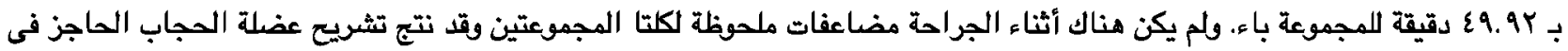

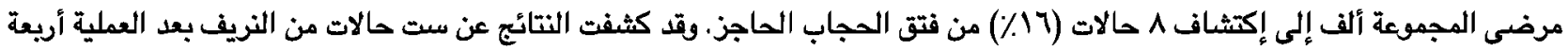

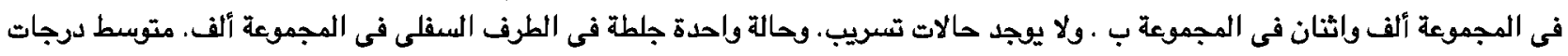

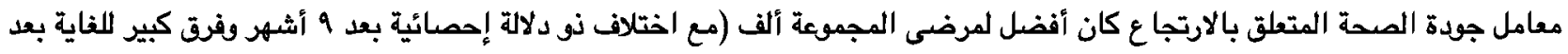

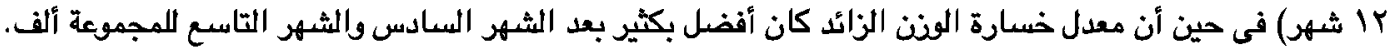

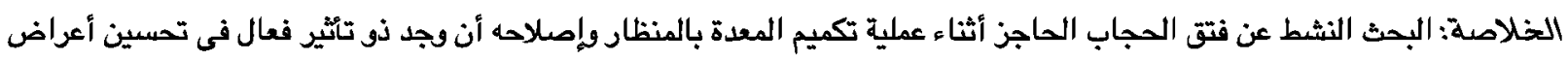
ارتجاع المرى" بعد العملية وتحسين فقدان الونذ مع زيادة مقبولة فى الوقت الإجمالى للعملية. 